\title{
Identification of biomarkers regulated by rexinoids (LGD1069, LG100268 and Ro25-7386) in human breast cells using Affymetrix microarray
}

\author{
HYE-SOOK SEO ${ }^{1}$, JONG-KYU WOO ${ }^{2}$, YONG CHEOL SHIN ${ }^{1}$ and SEONG-GYU KO ${ }^{1}$ \\ ${ }^{1}$ Laboratory of Clinical Biology and Pharmacogenomics and Center for Clinical Research and Genomics, \\ College of Korean Medicine, Kyung Hee University, Dongdaemun-gu, Seoul 130-701; ${ }^{2}$ Laboratory of Preventive Pharmacy, \\ College of Pharmacy, Gachon University of Medicine and Science, Yeonsu-gu, Incheon 406-840, Republic of Korea
}

Received June 11, 2014; Accepted February 26, 2015

DOI: $10.3892 / \mathrm{mmr} .2015 .3480$

\begin{abstract}
Retinoids possess anti-proliferative properties, which suggests that they possess chemopreventive and therapeutic potential against cancer. In the current study, genes modulated by rexinoids (retinoid $X$ receptor (RXR)-pan agonists, LGD1069 and LG100268; and the RXR $\alpha$ agonist, Ro25-7386) were identified using an Affymetrix microarray in normal and malignant breast cells. It was observed that LGD1069, LG100268 and Ro25-7386 suppressed the growth of breast cells. Secondly, several rexinoid-regulated genes were identified, which are involved in cell death, cell growth/maintenance, signal transduction and response to stimulus. These genes may be associated with the growth-suppressive activity of rexinoids. Therefore, the identified genes may serve as biomarkers and novel molecular targets for the prevention and treatment of breast cancer.
\end{abstract}

\section{Introduction}

Breast cancer is the most commonly diagnosed type of cancer in females and is the leading cause of cancer-related mortality in females worldwide (1). In 2013, the American Cancer Society estimated that 232,340 females would be newly diagnosed with breast cancer and 39,620 females would succumb to the disease (2). The key objectives of scientists and clinicians in managing this breast cancer are to prevent the incidence, detect it early and treat it with effective therapeutic strategies resulting in long overall survival with minimal

Correspondence to: Professor Seong-Gyu Ko, Laboratory of Clinical Biology and Pharmacogenomics and Center for Clinical Research and Genomics, College of Korean Medicine, Kyung Hee University, 26 Kyungheedae-ro, Dongdaemun-gu, Seoul 130-701, Republic of Korea

E-mail: epiko@khu.ac.kr

Key words: breast cancer, rexinoid, biomarker, LGD1069, LG100268, Ro25-7386 side effects. Therefore, the aim of the current study was to identify the genes associated with cell growth inhibition that are induced by Retinoid X receptor (RXR)-selective retinoids (rexinoids), with an aim to improve prevention and treatment of breast cancer.

Retinoids regulate a variety of biological functions, including embryogenesis, growth, differentiation, vision and reproduction (3-5). Retinoids additionally possess antiproliferative properties, which suggests a chemopreventive and therapeutic role against cancer (6). In addition, retinoids have been reported to inhibit normal- or tumor-cell growth through the regulation of differentiation and/or apoptosis (7-10).

Retinoids exert their effects in target cells via interaction with retinoic acid receptors (RARs) and RXRs. Each of these includes three subtypes, termed $\alpha, \beta$ and $\gamma$, which are encoded by distinct genes. The RAR $\alpha, \operatorname{RAR} \beta$ and RAR $\gamma$ genes have been localized to chromosomes 17q21, 3p24 and 12q13, respectively. The $\mathrm{RXR} \alpha, \mathrm{RXR} \beta$ and $\mathrm{RXR} \gamma$ genes have been mapped to chromosomes 9q34.3, 6p21.3 and 1q22-23, respectively (11). The RARs bind all-trans-retinoic acid (ATRA) and 9-cis-retinoic acid (RA) while RXRs bind 9-cis-RA alone. RXRs are known to heterodimerize with several steroid hormone receptors, including RAR, thyroid hormone receptor, vitamin D receptor, peroxisome proliferator-activated receptor, liver $\mathrm{X}$ receptor, pregnane $\mathrm{X}$ receptor and farnesoid $\mathrm{X}$ receptor suggesting its involvement in several signaling pathways (12). RXRs are also able to homodimerize in transfected cells (13).

In addition to naturally occurring retinoids, including ATRA, 9-cis-RA and 13-cis-RA, various synthetic retinoids with varied selectivity have been developed and are currently available to treat psoriasis, acne, photoaging, actinic keratosis and certain types of cancer, including acute promelocytic leukemia, cutaneous T-cell lymphoma and squamous or basal cell carcinoma (14). However, the use of RAR-selective retinoids is limited by their toxicity, which can result in chelitis, hypertriglyceridemia and hepatosplenomegaly (15).

Rexinoids are important in controlling apoptosis and can function in a ligand-dependent or ligand-independent manner $(16,17)$. Notably, rexinoids have been reported to suppress estrogen receptor (ER)-positive and ER-negative 
mammary tumor development with reduced toxicity compared with RAR-selective retinoids (18-20). Rexinoids are additionally active in animals with tamoxifen-resistant breast cancer $(17,21)$ and in ATRA-resistant breast cancer cells (22). Thus, rexinoids appear to be promising chemopreventive and therapeutic agents with improved efficiency as compared with RAR-selective ligands. Among the rexinoids, LGD1069 (Bexarotene) was confirmed as a safe and well-tolerated agent in clinical trials of cutaneous T-cell lymphoma, breast cancer and lung cancer $(22,23)$.

Thus, we focussed on rexinoids and their cognate receptor, $\mathrm{RXR}$, in breast cells, and aimed to investigate their regulatory activity on the transcription of genes involved in growth suppression. In particular, the present study investigated the $\mathrm{RXR} \alpha$ isoform, which has been suggested as a potential therapeutic target in breast cancer cells, due to the observation that overexpression of RXR $\alpha$ sensitized breast cancer cells lines to the antiproliferative effects of RXR-selective ligands (24). In addition, infection with adenoviral $\mathrm{RXR} \alpha$ induced nucleoplasmic overexpression of $\mathrm{RXR} \alpha$ and resulted in apoptosis with treatment with an RXR ligand in retinoid-resistant MDA-MB-231 cells (25). Thus, in the current study, the growth-suppressive activity of RXR pan agonists (LGD1069 and LG100268) and an RXR $\alpha$ specific ligand (Ro25-7386) were investigated in normal human mammary epithelial cells (HMECs) and four breast cancer cell lines (MCF-7, T47D, MDA-MB-231 and MDA-MB-435) using an MTS assay. Subsequently, the genes regulated by rexinoids that may be involved in their antiproliferative activity were investigated with an Affymetrix microarray.

\section{Materials and methods}

Ligands and antibodies. LGD1069 and LG100268 were provided by Ligand Pharmaceuticals, Inc. (La Jolla, CA, USA). Ro25-7386 was obtained from Roche Bioscience (Palo Alto, CA, USA). These compounds were diluted in dimethyl sulfoxide purchased from Sigma-Aldrich (St. Louis, MO, USA) to a final concentration of $0.1 \%$. Monoclonal or polyclonal antibodies (mouse or rabbit) against RXR $\alpha$ (cat. no. sc-553) B-cell lymphoma 2-associated X protein (Bax; cat. no. sc-7480), E-cadherin (cat. no. sc-7870), integrin $\alpha 6$ (cat. no. sc-13542), cell division control protein 42 (CDC42; cat. no. sc-8401) and actin (cat. no. sc-8432) were purchased from Santa Cruz Biotechnology, Inc. (Santa Cruz, CA, USA).

Cells and culture materials. Human normal mammary epithelial cells (HMECs) were obtained from Lonza Group (San Diego, CA, USA). Cells between passages 10 and 11 were used for experiments and the cells were grown and maintained in mammary epithelial basal medium supplemented with $13 \mathrm{mg} / \mathrm{ml}$ bovine pituitary extract, $0.5 \%$ serum, $5 \mu \mathrm{g} / \mathrm{ml}$ insulin, $10 \mathrm{ng} / \mathrm{ml}$ human recombinant epidermal growth factor, $0.5 \mathrm{mg} / \mathrm{ml}$ hydrocortisone, $50 \mu \mathrm{g} / \mathrm{ml}$ gentamicin and $50 \mu \mathrm{g} / \mathrm{ml}$ amphotericin- $\beta$ (all Clonetics, Lonza Group, San Diego, CA, USA). Cells were maintained in a humidified environment at $37^{\circ} \mathrm{C}$ with $5 \% \mathrm{CO}_{2}$ in air.

Four different human breast cancer cell lines (MCF-7, T47D, MDA-MB-231 and MBA-MB-435) purchased from the American Type Culture Collection (Manassas, VA, USA) were grown and maintained in appropriate growth media; minimal essential medium for MCF-7 and RPMI 1640 for T47D, MDA-MB-231 and MBA-MB-435 (Invitrogen Life Technologies, Carlsbad, CA, USA) supplemented with $10 \%$ heat-inactivated fetal bovine serum (FBS; Welgene, Daegu, Korea). L-glutamine, penicillin, streptomycin and gentamicin (Life Technologies Korea, LLC, Seoul, Korea) were used at the usual concentrations. For all experiments, breast cancer cells were harvested by trypsinization $(0.25 \%$ trypsin and $0.02 \%$ EDTA; Life Technologies Korea, LLC), seeded and grown in the appropriate media containing $10 \%$ FBS in a humidified $95 \%$ air $5 \% \mathrm{CO}_{2}$ atmosphere.

Cell growth rate measurements. The CellTiter $96^{\circledR} \mathrm{AQ}_{\text {ueous }}$ Non-Radioactive Cell Proliferation Assay (Promega Corporation, Madison, WI, USA) was used for the measurement of cell growth rate in breast cancer cells according to the manufacturer's instructions. The CellTiter $96^{\circledR} \mathrm{AQ}_{\text {ueous }}$ Assay is composed of solutions of a novel tetrazolium compound [3-(4,5-dimethylthiazol-2-yl)-5-(-carboxymethoxyphenyl)-

2-(4-sulfophenyl)-2H-tetrazolium, inner salt; MTS] and an electron coupling reagent (phenazine methosulfate; PMS). Briefly, HMECs, MCF-7 and T47D (1,000 cells/well) were plated in 96-well plates. Following a $24 \mathrm{~h}$ resting period, LGD1069, LG100268 and Ro25-7386 were added into the growth media and cell culture continued for 8-12 days. Each measurement day (every 2 days), MTS (Promega Corporation) was added to the cells ( $20 \mu 1$ combined MTS/PMS solution per $100 \mu \mathrm{l}$ culture medium) and further incubation was conducted for $2 \mathrm{~h}$. MTS is bioreduced by cells into a formazan product that is soluble in tissue culture medium. The absorbance of the formazan at $490 \mathrm{~nm}$ was measured directly using an ELISA plate reader (Gemini EM Microplate reader, Versa Max, Fluorescence readers; Molecular Devices, Sunnyvale, CA, USA). Each data point was performed in quadruplicate and the results were presented as the mean absorption (optical density).

RNA target preparation/Affymetrix microarray analysis. Total RNA was extracted from different breast cells treated with rexinoids using the guanidinium isothiocynate method (TRIzol reagent; Invitrogen Life Technologies) followed by purification using an RNeasy column (Qiagen, Valencia, CA, USA). RNA quality was assessed using the 2100 Bioanalyzer Instrument (Agilent Technologies, Inc., Palo Alto, CA, USA). A total of $10 \mu \mathrm{g}$ total RNA was processed for use on the microarray using the Affymetrix GeneChip One-Cycle Target Labeling kit (Affymetrix, Inc., Santa Clara, CA, USA) according to the manufacturer's instructions. The resultant biotinylated cRNA was fragmented and then hybridized to the Affymetrix U133 Plus 2.0 GeneChip. The arrays were washed, stained and scanned using the Affymetrix 450 Fluidics Station and GeneChip Scanner 3000 7G (Affymetrix, Inc.) according to the manufacturer's recommendations. Expression values were generated using Microarray Suite software, version 5.0 (Affymetrix, Inc.).

Statistical analysis of microarray data. Background subtraction and normalization using the robust multi-array average algorithm method was performed using GeneSpring GX 11.5 
Table I. Forward and reverse primers for amplification of targeted genes with reverse transcription-quantitative polymerase chain reaction.

\begin{tabular}{lll}
\hline Target gene & \multicolumn{1}{c}{ Forward primer } & \multicolumn{1}{c}{ Reverse primer } \\
\hline BAX & 5'-TGGAGCTGCAGAGGATGATTG-3' & 5'-GAAGTTGCCGTCAGAAAACATG-3' \\
E-cadherin & 5'-CACTGCCAACTGGCTGGAG-3' & 5'-GGGTTAGCTCAGCAGTAAAG-3' \\
FOXO3A & 5'-TCAATCAGAACTTGCTCCACCA-3' & 5'-GGACTCACTCAAGCCCATGTTG-3' \\
Integrin $\alpha 6$ & 5- TTTCCCGTTTCTTTCTTGAGTTGT-3' & 5'-TGGAAAAGGTAACTTGTGAGCCA-3' \\
Integrin $\beta 4$ & 5-TTCCAAATCACAGAGGAGAC-3 & 5-CTTGAGGTTGTCCAGATCAT-3' \\
PXN & 5'-TGGCTTCGCTGTCGGATTTC-3' & 5'GTCAAGGGCTGTCACCACTTTATC-3' \\
PTEN & 5'-AGAGCGTGCAGATAATGACAAG-3' & 5'-GGATCAGAGTCAGTGGTGTCAG-3' \\
STAT & 5'-CTGCTGCGGTTCAGTGAGAG-3' & 5'-CCAAGTGAAAGTGACCCCTCC-3' \\
Collagen type VI $\alpha 3$ & 5'-CTGGGCAGACATACCATGTG-3' & 5'-GCAAGTTCCTTCGTCTTTCG-3' \\
\hline
\end{tabular}

software (Agilent Technologies) for gene expression. Fold change values for genes were calculated as the ratio of the signal values of the experimental group compared with the control group. Alterations in gene expression $>2$-fold were considered to be statistically significant. Genes of interest were selected by referring to the PathArt program which shows intersection of genes in several signaling pathways.

Reverse transcription-quantitative polymerase chain reaction (RT-qPCR) analysis. Cells were cultured to $80-90 \%$ confluence. Total RNA was prepared using the Qiagen RNeasy Mini kit (Qiagen). The RT reaction was performed using $1 \mu \mathrm{g}$ total RNA which was reverse-transcribed into cDNA using a random hexamer primer (GeneAmp RNA PCR Core kit; Applied Biosystems Life Technologies, Foster City, CA, USA), according to the manufacturer's instructions. cDNA of the 7 selected genes and an internal reference gene (GAPDH) was produced from each sample and was quantified using a fluorescence-based real-time detection method (iCycler; Bio-Rad Laboratories, Inc., Hercules, CA, USA). RT-qPCR analysis was performed using the standard methods recommended by the RT-qPCR kit supplier (SYBR ${ }^{\circledR}$ Green Dye-Based Gene Expression Detection; Applied Biosystems Life Technologies). Primer sequences used for detection of RXR $\alpha$-regulated genes are shown in Table I (Cosmo Genetech, Seoul, Korea). For the endogenous control, human GAPDH labeled with VIC ${ }^{\mathrm{TM}}$ dye provided by Applied Biosystems Life Technologies was used. The amplification conditions were as follows: $30 \mathrm{sec}$ at $95^{\circ} \mathrm{C}$ and $3 \mathrm{~min}$ at $95^{\circ} \mathrm{C}$, and $30 \mathrm{sec}$ at $95^{\circ} \mathrm{C}$ and $60 \mathrm{sec}$ at $65^{\circ} \mathrm{C}$ for 40 cycles, followed by a final extension for $20 \mathrm{~min}$ at $72^{\circ} \mathrm{C}$. The ratio between the values obtained provided the relative gene expression levels.

Western blot analysis. Whole cell extracts were prepared using $1 \mathrm{X}$ sodium dodecyl sulfate (SDS) laemmlli lysis buffer (125 mM Tris-HCl, pH 6.8; $1 \%$ SDS; $2 \% \beta$-mercaptoethanol). Total cell lysates with equal quantities of protein $(30 \mu \mathrm{g})$ were subjected to $10 \%$ SDS-PAGE and subsequently electrotransferred onto a nitrocellulose membrane (Bio-Rad Laboratories, Inc.). Membranes were blocked with 5\% skimmed milk in PBST (phosphate-buffered saline containing 0.1\% Tween 20) for $1 \mathrm{~h}$ at room temperature, then incubated overnight with primary antibodies in PBST containing $2.5 \%$ bovine serum albumin (1:1,000 dilution). Subsequent to washing with PBST, the blot was further incubated for $1 \mathrm{~h}$ at room temperature with peroxidase conjugated anti-rabbit or anti-mouse antibodies (Pierce Technology Corporation, Holmdel, NJ, USA) in PBST and then visualized using the enhanced chemiluminescence system (GE Healthcare Life Sciences, Chalfont, UK). Protein expression was normalized using $\beta$-actin expression.

Statistical analysis. All experiments were performed in triplicate. Statistical analyses were performed using Microsoft Excel 2007 (Microsoft Corporation, Albuquerque, NM, USA). The data for the MTS assay and RT-qPCR are expressed as the mean \pm standard deviation. Student's t-test was used for single variable comparisons, and $\mathrm{P}<0.05$ was considered to indicate a statistically significant difference.

\section{Results}

Anti-proliferative activity of rexinoids. In Fig. 1, the structures of LGD1069 and LG100268 are presented. The anti-proliferative effects of rexinoids in normal and malignant breast cells were investigated. It was observed that LGD1069 and LG100268 significantly suppressed cell growth in HMECs at $10 \mu \mathrm{M}$; whereas co-treatment with LGD1069 and LG100268 reduced cell growth at 1 and $10 \mu \mathrm{M}$ suggesting that these two rexinoids possess the capacity to prevent mammary cell growth (Fig. 2). By contrast, LGD1069 weakly (10 $\mu \mathrm{M}$, $\mathrm{P}<0.05)$ inhibited cell growth in MCF-7 cells while the compound strongly and significantly suppressed cell growth in a dose-dependent manner in T47D cells $(0.1 \mu \mathrm{M}, \mathrm{P}<0.01$; 1 and $10 \mu \mathrm{M}, \mathrm{P}<0.001$ ) (Fig. 3). Notably, LGD1069 induced mild inhibition $(\mathrm{P}<0.05)$ of cell growth in MDA-MB-231 cells at $10 \mu \mathrm{M}$ while rexinoids did not affect cell growth in MDA-MB-435 cells (Fig. 3). This result indicates that LGD1069 is able to inhibit the growth of ER-negative breast cancer with therapeutic potency.

In addition, Ro25-7386, the RXR $\alpha$ agonist significantly suppressed cell growth in a dose-dependent manner in HMECs. Ro25-7386 strongly reduced T47D cell growth at $1 \mu \mathrm{M}$ and induced suppression of cell growth in MCF-7 cells at day 8 at $1 \mu \mathrm{M}$ (Fig. 4). These results suggest that RXR $\alpha$ is 


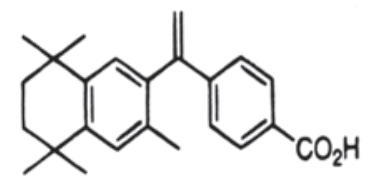

LGD1069

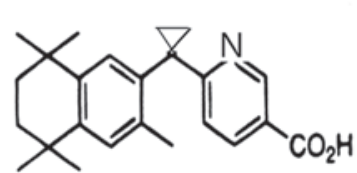

LG100268

Figure 1. Molecular structure of LGD1069 and LG100268.

HMECS

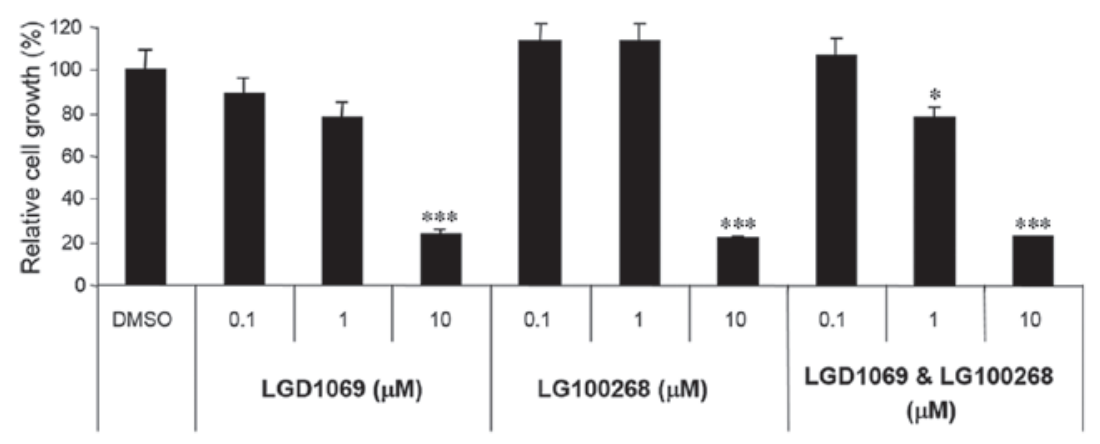

Figure 2. Effect of LGD1069 and LG100268 on the growth of HMECs. HMECs were treated with different doses of LGD1069 and/or LG100268 (0.1-10 $\mu$ M). The relative cell growth rate was measured by an MTS assay after 10 days. The growth rate of the vehicle-treated cells was set to $100 \%$ and the relative reduction in cell viability resulting from the treatment with rexinoids was expressed as a percentage of the control. Data are presented as the mean of three independent experiments (error bars denote the standard deviation; ${ }^{\prime} \mathrm{P}<0.05,{ }^{* *} \mathrm{P}<0.01$ and ${ }^{* * *} \mathrm{P}<0.001$ vs. control). HMECs, human mammary epithelial cells; DMSO, dimethyl sulfoxide.


Figure 3. Effect of LGD1069 and LG100268 on the growth of breast cancer cells. MCF-7, T47D, MDA-MB-231 and MDA-MB-435 cells were treated with different doses of LGD1069 or LG100268 (0.1-10 $\mu \mathrm{M})$. The relative cell growth rate was measured by an MTS assay after 10 days. The growth rate of the vehicle-treated cells was set to $100 \%$, and the relative reduction in cell viability resulting from the treatment with rexinoids was expressed as a percentage of the control. Data are presented as the mean of three independent experiments (error bars denote the standard deviation; ${ }^{*} \mathrm{P}<0.05,{ }^{* *} \mathrm{P}<0.01$ and ${ }^{* * *} \mathrm{P}<0.001 \mathrm{vs}$. control). DMSO, dimethyl sulfoxide.

important in the suppression of growth induced by rexinoids in breast cells.

Expression of $R X R \alpha$ in breast cells. The RXR $\alpha$ level in normal and malignant breast cells was next determined. It was observed that all breast cell lines express RXR $\alpha$ but with different intensities. MCF-7 and T47D expressed higher levels of RXR $\alpha$ (Fig. 5). Notably, the ER-negative breast cancer cell lines, MDA-MB-231 and MDA-MB-435, also expressed RXR $\alpha$.

Identification of target genes regulated by rexinoids in normal and malignant breast cells by Affymetrix microarray. Finally, the genes regulated by rexinoids in normal (HMECs) and 
Table II. Genes up- and downregulated by Ro25-7386 in human mammary epithelial cells.

A, Genes upregulated by Ro25-7386

\begin{tabular}{|c|c|c|}
\hline Probe set & Gene & Fold change \\
\hline 213872_at & $\begin{array}{l}\text { gb:BE465032/DB_XREF=gi:9510807/DB_XREF=hv76g09.x1/CLONE= IMAGE:3179392/ } \\
\text { FEA=EST/CNT=34/TID=Hs.173685.1/TIER=Stack/STK=15/UG=Hs. 173685/LL= 81688/ } \\
\text { UG_GENE=FLJ12619/UG_TITLE=hypothetical protein FLJ12619 }\end{array}$ & 27.55 \\
\hline 204989_s_at & Integrin, $\beta 4$ & 26.60 \\
\hline 210317_s_at & Tyrosine 3-monooxygenase/tryptophan 5-monooxygenase activation protein, epsilon polypeptide & 22.14 \\
\hline 200935_at & Calreticulin & 21.26 \\
\hline 201130_s_at & Cadherin 1, type 1, E-cadherin (epithelial) & 20.66 \\
\hline 201123_s_at & Eukaryotic translation initiation factor $5 \mathrm{~A}$ & 19.04 \\
\hline 200751_s_at & Heterogeneous nuclear ribonucleoprotein $\mathrm{C}(\mathrm{C} 1 / \mathrm{C} 2)$ & 18.97 \\
\hline 214007_s_at & PTK9 protein tyrosine kinase 9 & 17.37 \\
\hline 203392_s_at & C-terminal binding protein 1 & 16.35 \\
\hline 204427_s_at & Coated vesicle membrane protein & 16.00 \\
\hline 216971_s_at & Plectin 1 , intermediate filament binding protein $500 \mathrm{kDa}$ & 15.17 \\
\hline 217211_at & $\begin{array}{l}\text { Consensus includes gb:D50604/DEF=Human } \beta \text {-cytoplasmic actin (ACTBP9) } \\
\text { pseudogene/FEA=CDS/DB_XREF=gi:2094759/UG=Hs.248007 Human } \beta \text {-cytoplasmic } \\
\text { actin (ACTBP9) pseudogene }\end{array}$ & 14.35 \\
\hline 215780_s_at & SET translocation (myeloid leukemia-associated) & 12.51 \\
\hline 201971_s_at & ATPase, $\mathrm{H}^{+}$transporting, lysosomal $70 \mathrm{kDa}, \mathrm{V} 1$ subunit $\mathrm{A}$ & 11.75 \\
\hline 204426_at & Coated vesicle membrane protein & 11.74 \\
\hline 220494_s_at & $\begin{array}{l}\text { gb:NM_018678.1/DEF=Homo sapiens lipopolysaccharide specific response-68 protein } \\
\text { (LSR68), mRNA./FEA=mRNA/GEN=LSR68/PROD=lipopolysaccharide specific } \\
\text { response-68 protein/DB_XREF=gi:8923914/UG=Hs.103189 lipopolysaccharide specific } \\
\text { response-68 protein/ }\end{array}$ & 11.18 \\
\hline 215177_s_at & Integrin, $\alpha 6$ & 10.97 \\
\hline 215434_x_at & AG1 & 10.35 \\
\hline 214693_x_at & $\begin{array}{l}\text { Hypothetical protein MGC8902///AG1///hypothetical protein DJ328E19.C1.1///hypothetical } \\
\text { protein LOC200030///hypothetical protein LOC348482 }\end{array}$ & 10.34 \\
\hline 211905_s_at & Integrin, $\beta 4$ & 10.34 \\
\hline 201048_x_at & RAB6A, member RAS oncogene family & 10.03 \\
\hline 214701_s_at & Fibronectin 1 & 10.01 \\
\hline 210092_at & Mago-nashi homolog, proliferation-associated (Drosophila) & 9.74 \\
\hline 212107_s_at & DEAH (Asp-Glu-Ala-His) box polypeptide 9 & 9.68 \\
\hline 202118_s_at & Copine III & 9.48 \\
\hline 217234_s_at & Villin 2 (ezrin) & 9.09 \\
\hline 208853_s_at & Calnexin & 7.59 \\
\hline 201742_x_at & Splicing factor, arginine/serine-rich 1 (splicing factor 2, alternate splicing factor) & 7.44 \\
\hline 208750_s_at & ADP-ribosylation factor 1 & 7.31 \\
\hline 203803_at & Prenylcysteine oxidase 1 & 7.31 \\
\hline 211162_x_at & Stearoyl-CoA desaturase ( $\delta$-9-desaturase) & 7.30 \\
\hline 202856_s_at & Solute carrier family 16 (monocarboxylic acid transporters), member 3 & 7.26 \\
\hline 200796_s_at & Myeloid cell leukemia sequence 1 (BCL2-related) & 7.25 \\
\hline 213606_s_at & Rho GDP dissociation inhibitor (GDI) $\alpha$ & 7.25 \\
\hline 201373_at & Plectin 1 , intermediate filament binding protein $500 \mathrm{kDa}$ & 7.19 \\
\hline 208057_s_at & GLI-Kruppel family member GLI2 & 7.04 \\
\hline 217294_s_at & Enolase $1,(\alpha)$ & 6.99 \\
\hline 213875_x_at & Chromosome 6 open reading frame 62 & 6.93 \\
\hline 91816_f_at & Ring finger and $\mathrm{KH}$ domain containing 1 & 6.90 \\
\hline 200806_s_at & Heat shock 60 kDa protein 1 (chaperonin) & 6.69 \\
\hline 214845_s_at & Calumenin & 6.66 \\
\hline 211823_s_at & Paxillin & 5.75 \\
\hline 206665_s_at & BCL2-like 1 & 5.40 \\
\hline
\end{tabular}


Table II. Continued.

\begin{tabular}{|c|c|c|}
\hline Probe set & Gene & Fold change \\
\hline 208637_x_at & Actinin, $\alpha 1$ & 5.11 \\
\hline 208677_s_at & Basigin (OK blood group) & 4.66 \\
\hline 221499_s_at & Syntaxin 16 & 4.16 \\
\hline 209226_s_at & Transportin 1 & 3.90 \\
\hline 201752_s_at & Adducin $3(\gamma)$ & 3.90 \\
\hline 200766_at & Cathepsin D (lysosomal aspartyl protease) & 3.90 \\
\hline 203085_s_at & Transforming growth factor, $\beta 1$ (Camurati-Engelmann disease) & 3.75 \\
\hline 211833_s_at & BCL2-associated X protein & 3.65 \\
\hline 208852_s_at & Calnexin & 3.49 \\
\hline 210655_s_at & Forkhead box O3A & 3.33 \\
\hline
\end{tabular}

B, Genes downregulated by Ro25-7386

\begin{tabular}{|c|c|c|}
\hline Probe set & Gene & Fold chang \\
\hline 203991_s_at & Ubiquitously transcribed tetratricopeptide repeat, $\mathrm{X}$ chromosome & -5.32 \\
\hline 220568_at & $\begin{array}{l}\text { gb:NM_018582.1/DEF=Homo sapiens hypothetical protein PRO1483 (PRO1483), } \\
\text { mRNA./FEA=mRNA/GEN=PRO1483/PROD=hypothetical protein PRO1483/DB_ } \\
\text { XREF=gi:8924047/UG=Hs.279694 hypothetical protein PRO1483/FL=gb:AF116635.1 } \\
\text { gb:NM_018582.1 }\end{array}$ & -4.72 \\
\hline 213705_at & Methionine adenosyltransferase II, $\alpha$ & -4.64 \\
\hline 201438_at & Collagen, type VI, $\alpha 3$ & -4.59 \\
\hline 217665_at & $\begin{array}{l}\text { Consensus includes gb:AA420614/FEA=EST/DB_XREF=gi:2094586/DB_XREF=est: } \\
\text { nc62g02.r1/CLONE=IMAGE:745874/UG=Hs.188826 ESTs, Moderately similar to G02654 } \\
\text { ribosomal protein L39 H. sapiens }\end{array}$ & -4.17 \\
\hline 209459_s_at & 4-aminobutyrate aminotransferase & -3.99 \\
\hline 220992_s_at & Chromosome 1 open reading frame $25 / / /$ chromosome 1 open reading frame 25 & -3.81 \\
\hline 222294_s_at & Eukaryotic translation initiation factor $2 \mathrm{C}, 2$ & -3.78 \\
\hline 221995_s_at & $\begin{array}{l}\text { Consensus includes gb:BF195165/FEA=EST/DB_XREF=gi:11081754/DB_XREF=est: } \\
\text { 7n16b01.x1/CLONE=IMAGE:3564624/UG=Hs.182695 hypothetical protein MGC3243 }\end{array}$ & -3.71 \\
\hline 215095_at & Esterase D/formylglutathione hydrolase & -3.68 \\
\hline 212675_s_at & KIAA0582 & -3.66 \\
\hline 210187_at & FK506 binding protein $1 \mathrm{~A}, 12 \mathrm{kDa}$ & -3.65 \\
\hline 204634_at & NIMA (never in mitosis gene a)-related kinase 4 & -3.59 \\
\hline 203791_at & Dmx-like 1 & -3.53 \\
\hline 205583_s_at & Chromosome $\mathrm{X}$ open reading frame 45 & -3.53 \\
\hline 218352_at & Regulator of chromosome condensation ( $\mathrm{RCC} 1)$ and $\mathrm{BTB}(\mathrm{POZ})$ domain containing protein 1 & -3.52 \\
\hline 209788_s_at & Type 1 tumor necrosis factor receptor shedding aminopeptidase regulator & -3.48 \\
\hline 212959_s_at & MGC4170 protein & -3.47 \\
\hline 205802_at & Transient receptor potential cation channel, subfamily C, member 1 & -3.43 \\
\hline 202732_at & Protein kinase (cAMP-dependent, catalytic) inhibitor $\gamma$ & -3.40 \\
\hline 202149_at & Neural precursor cell expressed, developmentally downregulated 9 & -3.39 \\
\hline 213225_at & Protein phosphatase 1B (formerly $2 \mathrm{C}$ ), magnesium-dependent, $\beta$ isoform & -3.39 \\
\hline 213624_at & Sphingomyelin phosphodiesterase, acid-like 3A & -3.39 \\
\hline 207855_s_at & Mid-1-related chloride channel 1 & -3.37 \\
\hline 204415_at & Interferon, $\alpha$-inducible protein (clone IFI-6-16) & -3.29 \\
\hline 210017_at & Mucosa associated lymphoid tissue lymphoma translocation gene 1 & -3.12 \\
\hline 205420_at & Peroxisomal biogenesis factor 7 & -3.05 \\
\hline 219317_at & Polymerase (DNA directed) iota & -3.01 \\
\hline 204176_at & Kelch-like ECT2 interacting protein & -3.00 \\
\hline 203741_s_at & Adenylate cyclase 7 & -2.95 \\
\hline 205034_at & Cyclin E2 & -2.94 \\
\hline 204078_at & Synaptonemal complex protein SC65 & -2.90 \\
\hline
\end{tabular}


Table II. Continued.

Probe set

Gene

Fold change

203881_s_at Dystrophin (muscular dystrophy, Duchenne and Becker types)

209717_at Ecotropic viral integration site 5

213473_at

BRCA1 associated protein

215949_x_at Immunoglobulin heavy constant $\mu$

205668_at Lymphocyte antigen 75

$-2.83$

219688_at Bardet-Biedl syndrome 7

$-2.82$

207845_s_at

208920_at

Anaphase promoting complex subunit 10

$-2.80$

218002_s_at

Sorcin

$-2.79$

208727_s_at

Chemokine (C-X-C motif) ligand 14

$-2.53$

Cell division cycle 42 (GTP binding protein, $25 \mathrm{kDa}$ )

$-2.25$
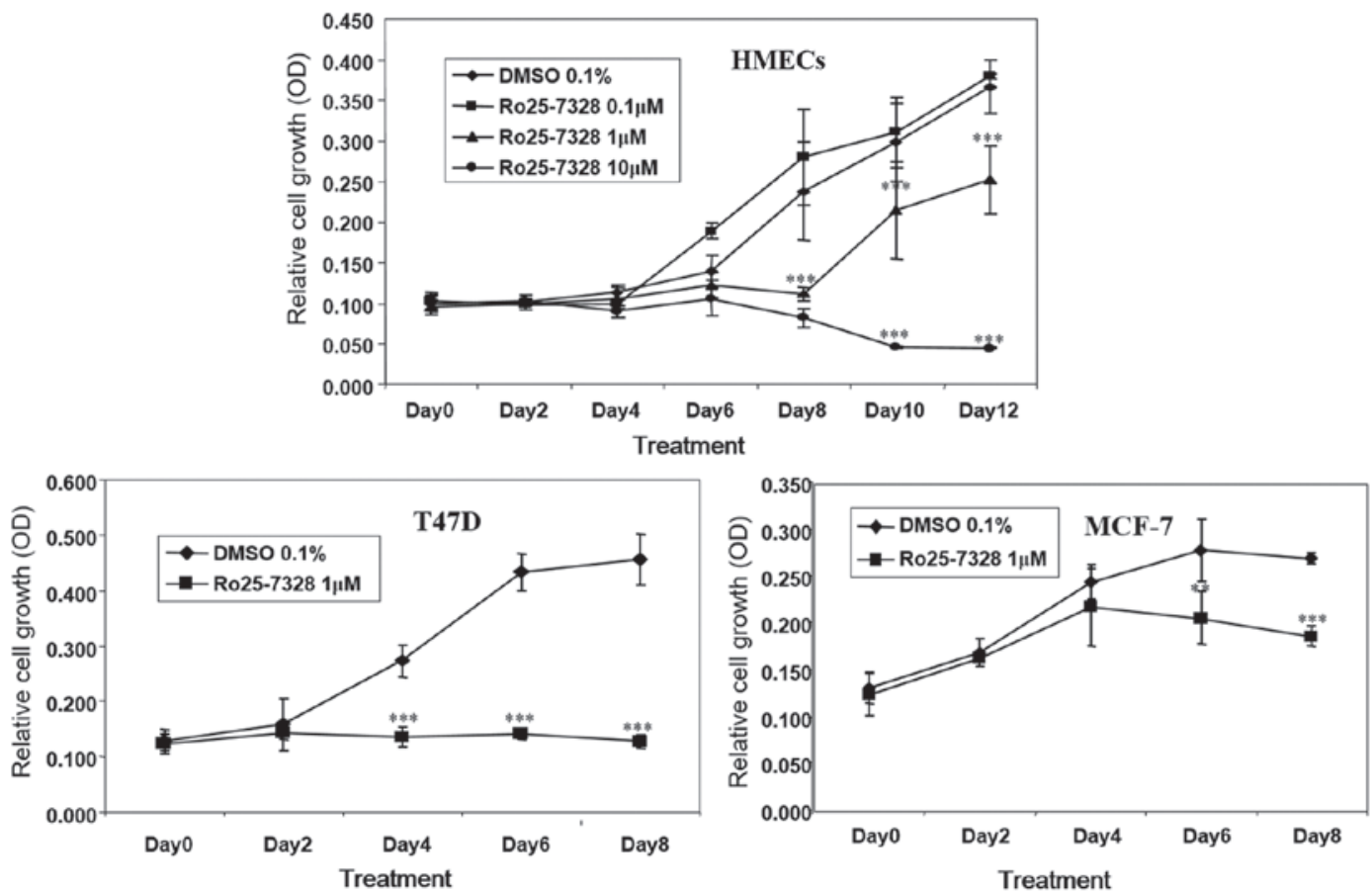

Figure 4. Effect of Ro25-7386 on the growth of breast cells. HMECs, MCF-7 and T47D cells were treated with Ro25-7386 for 0-12 days. The relative cell growth rate was measured by an MTS assay. Data are presented as the mean of three independent experiments (error bars denote the standard deviation; ${ }^{*} \mathrm{P}<0.05,{ }^{* *} \mathrm{P}<0.01$ and ${ }^{* * *} \mathrm{P}<0.001$ vs. control). DMSO, dimethyl sulfoxide; OD, optical density.

malignant (MCF-7, T47D and MDA-MB-231) breast cells were identified. Gene expression profiles were established using the Affymetrix microarray (human genome U133A 2.0). Among them, several genes involved in cell death, cell growth/maintenance, signal transduction and response to stimulus were identified.

In HMECs, 638 genes upregulated and 347 genes downregulated by Ro25-7386 with alterations in fold induction $>2$-fold were identified. A total of 22 genes were strongly upregulated ( $>10$-fold) and 5 genes were strongly downregulated ( $>4$-fold) in expression levels by Ro25-7386 (Table IIA and $\mathrm{B})$. Among them, several genes were notable, including integrin $\beta 4$, E-cadherin (CDH1), C-terminal binding protein 1 (CtBP1), integrin $\alpha 6$, paxillin (PAX), BAX, forkhead box O3A (FOXO3A) and signal transducer and activator of transcription 3 (STAT3) (upregulated genes), and collagen type VI $\alpha 3$ and cell division cycle 42 (CDC42) (downregulated genes).

In MCF-7 cells, 83 genes were upregulated and 98 genes were downregulated by Ro25-7328 with alterations in fold induction $>2$-fold were identified (Table III). Among them, several genes were recognized including transforming growth factor $\beta 2$, immunoglobulin heavy constant $\gamma 1$, protein kinase $\mathrm{C} \delta$ binding protein, interleukin 6 receptor and neurophilin 2 (upregulated genes), and cathepsin S, zinc finger protein 36, integrin $\beta 4$, transforming growth factor $\beta 1, \mathrm{PAX}$ and $\mathrm{CtBP} 1$ (downregulated genes).

In T47D cells, 16 upregulated genes and 3 downregulated genes modulated by LGD1069 were observed (Table IV), whereas 3 upregulated genes and 5 downregulated genes 
Table III. Genes up- and downregulated by Ro25-7386 in MCF-7 cells.

A, Genes upregulated by Ro25-7386

Probe set

Gene

Fold change

209909_s_at

Transforming growth factor, $\beta 2$

4.94

211430_s_at

Immunoglobulin heavy constant $\gamma 1$ (G1m marker)

3.82

213010_at

Protein kinase $\mathrm{C}, \delta$ binding protein

3.76

63825_at

Abhydrolase domain containing 2

3.40

208993_s_at

Peptidyl-prolyl isomerase $\mathrm{G}$ (cyclophilin G)

3.39

204681_s_at

Rap guanine nucleotide exchange factor (GEF) 5

3.26

213536_s_at

gb:AA910614/DB_XREF=gi:3049904/DB_XREF=ok61b04.s1/CLONE=IMAGE:

3.20

1518415/FEA=EST/CNT=42/TID=Hs .84285.2/TIER=Stack/STK=12/UG=Hs.

84285/LL=7329/UG_GENE=UBE2I/UG_TITLE=ubiquitin-conjugating enzyme E2I

(homologous to yeast UBC9)

213087_s_at

Eukaryotic translation elongation factor $1 \delta$ (guanine nucleotide exchange protein)

3.09

217489_s_at

Interleukin 6 receptor

3.07

205443_at

Small nuclear RNA activating complex, polypeptide 1, $43 \mathrm{kDa}$

213747_at

Consensus includes gb:AA047234/FEA=EST/DB_XREF=gi:1525134/DB_XREF=

est:zf50b09.s1/CLONE=IMAGE:380345/UG=Hs.223014 antizyme inhibitor

221815_at

Abhydrolase domain containing 2

3.04

2.99

212451_at

KIAA0256 gene product

2.95

Butyrobetaine $(\gamma)$, 2-oxoglutarate dioxygenase ( $\gamma$-butyrobetaine hydroxylase) 1

2.93

205363_at

212952_at

Consensus includes gb:AA910371/FEA=EST/DB_XREF=gi:3049661/DB_XREF=est:

2.92

ok83h10.s1/CLONE=IMAGE:1520611/UG=Hs.16488 calreticulin

210136_at

Myelin basic protein

2.90

214255_at

213789_at

ATPase, class V, type 10A

2.88

Consensus includes gb:N58493/FEA=EST/DB_XREF=gi:1202383/DB_XREF=est:

2.87

yv72d01.s1/CLONE=IMAGE:248257/UG=Hs.75105 emopamil-binding protein

(sterol isomerase)

217464_at

Consensus includes gb:L48784/DEF=050 Homo sapiens cDNA/FEA=mRNA/DB_XREF= gi:1066715/UG=Hs.182426 ribosomal protein S2

210841_s_at Neuropilin 2

2.86

204378_at

208859_s_at

Breast carcinoma amplified sequence 1

221018_s_at

218876_at

$\alpha$ thalassemia/mental retardation syndrome X-linked (RAD54 homolog, S. cerevisiae)

Tudor domain containing $1 / / /$ tudor domain containing 1

Brain specific protein///brain specific protein

215081_at

KIAA1024 protein

201510_at

210089_s_at

E74-like factor 3 (ets domain transcription factor, epithelial-specific )

2.83

2.82

2.80

2.76

2.76

2.73

2.71

2.69

2.68

2.65

Chromosome 20 open reading frame 6

2.64

211626_x_at

v-ets erythroblastosis virus E26 oncogene like (avian)///v-ets erythroblastosis virus E26

oncogene like (avian)

214316_x_at gb:AI378706/DB_XREF=gi:4188559/DB_XREF=tb91f09.x1/CLONE=IMAGE:2061737/

2.64

$\mathrm{FEA}=\mathrm{EST} / \mathrm{CNT}=13 / \mathrm{TID}=\mathrm{Hs} .16488 .3 / \mathrm{TIER}=\mathrm{Stack} / \mathrm{STK}=13 / \mathrm{UG}=\mathrm{Hs} .16488 / \mathrm{LL}=811 / \mathrm{UG}$

_GENE=CALR/UG_TITLE=calreticulin

220657_at

Kelch-like 11 (Drosophila)

2.61

206490_at

Discs, large (Drosophila) homolog-associated protein 1

2.60

2.59

Phosphoenolpyruvate carboxykinase 1 (soluble)

2.59

214884_at

gb:AL033403/DB_XREF=gi:3859054/FEA=mRNA/CNT=15/TID=Hs $.89543 .1 /$ TIER=

ConsEnd/STK=0/UG=Hs.89543/LL=4168/UG_GENE=MCF2/UG_TITLE=MCF.2 cell line

derived transforming sequence/DEF=Human DNA sequence from clone 88D7 on chromosome

Xq25-26.3 Contains F9 (coagulation factor IX (plasma thromboplastic component, Christmas

disease, haemophilia B)), dbl oncogene. EST, STS, GSS

201506_at

Transforming growth factor, $\beta$-induced, $68 \mathrm{kDa}$

213979_s_at

Consensus includes gb:BF984434/FEA=EST/DB_XREF=gi:12387246/DB_XREF=est:

602307971F1/CLONE=IMAGE:4399313/UG=Hs.239737 C-terminal binding protein 1 
Table III. Continued.

\begin{tabular}{|c|c|c|}
\hline Probe set & Gene & Fold change \\
\hline 211253_x_at & Peptide YY & 2.38 \\
\hline 206879_s_at & Neuregulin 2 & 2.33 \\
\hline 208835_s_at & Cisplatin resistance-associated overexpressed protein & 2.33 \\
\hline 201506_at & Transforming growth factor, $\beta$-induced, $68 \mathrm{kDa}$ & 2.18 \\
\hline
\end{tabular}

B, Genes downregulated by Ro25-7386

Probe set

202901_x_at 201367_s_at 213606_s_at 211136_s_at 204989_s_at 213042_s_at 216971_s_at 201167_x_at 219529_at

218813_s_at 211905_s_at 211672_s_at

207521_s_at 213986_s_at 207824_s_at 203085 s_at 203953_s_at 211019_s_at 209872_s_at 214326_x_at 208677_s_at 201245_s_at 203751_x_at 203370_s_at 203028_s_at 210954_s_at 211823_s_at 200968_s_at 205463_s_at 210317_s_at

211300_s_at 214251_s_at 207722_s_at 216969_s_at 203809_s_at 218848_at 212090_at

201373_at 218302_at 213887_s_at 201369_s_at
Gene

Fold change

Cathepsin S

Zinc finger protein 36, C3H type-like 2

$-64.37$

$-5.67$

Rho GDP dissociation inhibitor (GDI) $\alpha$

$-5.01$

Cleft lip and palate associated transmembrane protein 1

$-4.59$

Integrin, $\beta 4$

$-4.51$

$-4.42$

ATPase, $\mathrm{Ca}++$ transporting, ubiquitous

$-4.37$

Plectin 1, intermediate filament binding protein $500 \mathrm{kDa}$

$-4.14$

Rho GDP dissociation inhibitor (GDI) $\alpha$

$-3.97$

Chloride intracellular channel 3

$-3.93$

GRB2-like endophilin B2

$-3.87$

$-3.70$

Actin related protein $2 / 3$ complex, subunit $4,20 \mathrm{kDa} / / /$ actin related protein $2 / 3$ complex, subunit 4, 20kDa

ATPase, $\mathrm{Ca}++$ transporting, ubiquitous

$-3.44$

Chromosome 19 open reading frame 6

$-3.43$

MYC-associated zinc finger protein (purine-binding transcription factor)

$-3.42$

Transforming growth factor, $\beta 1$ (Camurati-Engelmann disease)

$-3.34$

Claudin 3

$-3.26$

$-3.22$

$-3.20$

$-3.14$

Jun D proto-oncogene

$-3.12$

$-3.08$

$-3.08$

$-3.05$

$-3.02$

$-2.99$

$-2.97$

$-2.93$

$-2.87$

$-2.87$

Tyrosine 3-monooxygenase/tryptophan 5-monooxygenase activation protein, $\varepsilon$ polypeptide

Tumor protein p53 (Li-Fraumeni syndrome)

$-2.84$

$-2.81$

$-2.80$

$-2.79$

$-2.76$

$-2.73$

$-2.69$

Glutamate receptor, ionotropic, N-methyl D-asparate-associated protein 1 (glutamate binding)

Plectin 1, intermediate filament binding protein $500 \mathrm{kDa}$

Presenilin enhancer 2

Polymerase (RNA) II (DNA directed) polypeptide E, $25 \mathrm{kDa}$

$-2.67$ 
Table III. Continued.

\begin{tabular}{lll}
\hline Probe set & \multicolumn{1}{c}{ Gene } & Fold change \\
\hline 203392_s_at & C-terminal binding protein 1 & -2.50 \\
200796_s_at & Myeloid cell leukemia sequence 1 (BCL2-related) & -2.43 \\
206665_s_at & BCL2-like 1 & -2.35
\end{tabular}

Table IV. Genes up- and downregulated by LGD1069 in T47D cells.

A, Genes upregulated by LGD1069

Probe set

Gene

Fold change

215653_at Consensus includes gb:AF339805.1/DEF=Homo sapiens clone IMAGE:248602, mRNA

4.74

sequence./FEA=mRNA/DB_XREF=gi:13507343/UG=Hs.326719 Homo sapiens clone

IMAGE:248602, mRNA sequence

206424_at Cytochrome P450, family 26, subfamily A, polypeptide 1

202481_at Dehydrogenase/reductase (SDR family) member 3

211689_s_at Transmembrane protease, serine 2///transmembrane protease, serine 2

213629_x_at Metallothionein 1F (functional)

Consensus includes gb:AK022102.1/DEF=Homo sapiens cDNA FLJ12040 fis, clone

HEMBB1001944./FEA=mRNA/DB_XREF=gi:10433423/UG=Hs.296687 Homo sapiens

cDNA FLJ12040 fis, clone HEMBB1001944

208581_x_at Metallothionein 1X

210827_s_at E74-like factor 3 (ets domain transcription factor, epithelial-specific )

217165_x_at Metallothionein $1 \mathrm{~F}$ (functional)

204326_x_at Metallothionein 1X

Metallothionein $1 \mathrm{H}$

204745_x_at Metallothionein $1 \mathrm{G}$

Chemokine (C-X-C motif) receptor 4

212185_x_at Consensus includes gb:NM_005953.1/DEF=Homo sapiens metallothionein 2A (MT2A), mRNA

$\mathrm{FEA}=\mathrm{CDS} / \mathrm{GEN}=\mathrm{MT} 2 \mathrm{~A} / \mathrm{PROD}=$ metallothionein 2A/DB_XREF=gi:5174763/UG=Hs.118786 metallothionein 2A/FL=gb:NM_005953.1

211456_x_at gb:AF333388.1/DB_XREF=gi:13310411/FEA=FLmRNA/CNT=1/TID=Hs.326774.0/TIER= $\mathrm{FL} / \mathrm{STK}=0 / \mathrm{UG}=\mathrm{Hs} .326774 / \mathrm{DEF}=$ Homo sapiens metallothionein $1 \mathrm{H}$-like protein mRNA, complete cds./PROD=metallothionein $1 \mathrm{H}$-like protein/FL=gb:AF333388.1

B, Genes downregulated by LGD1069

\begin{tabular}{llll}
\hline Probe set & & Gene & Fold change \\
\hline 207437_at & Neuro-oncological ventral antigen 1 & -3.04 \\
210806_at & KIAA0998 & -2.33 \\
202989_at & Regulator of G-protein signaling 1 & -2.13 \\
\hline
\end{tabular}

were identified to be modulated by LG100268 (Table V) with alterations in fold induction $>2$-fold. According to the data, several notable genes induced by LGD1069 and LG100268 in T47D cells were identified, including cytochrome P450, dehydrogenase/reductase member 3 , metallothionein, neuro-oncological ventral antigen 1 and regulator of G-protein signaling 1 (for LGD1069), and chemokine, glutamate receptor, colon carcinoma-related protein and insulin-like growth factor binding protein 7 (for LG100268). In addition, 3 upregulated genes and 5 downregulated genes by Ro25-7386 were identified with alterations in fold induction $>2$-fold in T47D cells. Among them, chemokine (upregulated genes), and glutamate receptor, ionotropic kainite 2 , colon carcinoma-related protein, insulin-like growth factor binding protein 7 and growth differentiation factor 8 were identified (Table VI). 
Table V. Genes up- and downregulated by LG100268 in T47D cells.

A, Genes upregulated by LG100268

Probe set

Gene

Fold change

215653_at Consensus includes gb:AF339805.1/DEF=Homo sapiens clone IMAGE:248602, mRNA sequence./FEA=mRNA/DB_XREF=gi:13507343/UG=Hs.326719 Homo sapiens clone IMAGE:248602, mRNA sequence

215924_at Consensus includes gb:AK022102.1/DEF=Homo sapiens cDNA FLJ12040 fis, clone HEMBB1001944./FEA=mRNA/DB_XREF=gi:10433423/UG=Hs.296687 Homo sapiens cDNA FLJ12040 fis, clone HEMBB1001944

204470_at Chemokine (C-X-C motif) ligand 1 (melanoma growth stimulating activity, $\alpha$ )

B, Genes downregulated by LG100268

\begin{tabular}{|c|c|c|}
\hline Probe set & Gene & Fold chang \\
\hline 215655_at & Glutamate receptor, ionotropic, kainate 2 & -3.29 \\
\hline 220327_at & Colon carcinoma-related protein & -2.94 \\
\hline 213910_at & Insulin-like growth factor binding protein 7 & -2.66 \\
\hline 207145_at & Growth differentiation factor 8 & -2.49 \\
\hline 210806_at & KIAA0998 & -2.30 \\
\hline
\end{tabular}

Table VI. Genes up- and downregulated by Ro25-7386 in T47D cells.

A, Genes upregulated by Ro25-7386

\begin{tabular}{|c|c|c|}
\hline Probe set & Gene & Fold change \\
\hline 215653_at & $\begin{array}{l}\text { Consensus includes gb:AF339805.1/DEF=Homo sapiens clone IMAGE:248602, mRNA } \\
\text { sequence./FEA=mRNA/DB_XREF=gi:13507343/UG=Hs.326719 Homo sapiens clone } \\
\text { IMAGE:248602, mRNA sequence }\end{array}$ & 4.74 \\
\hline 215924_at & $\begin{array}{l}\text { Consensus includes gb:AK022102.1/DEF=Homo sapiens cDNA FLJ12040 fis, clone } \\
\text { HEMBB1001944./FEA=mRNA/DB_XREF=gi:10433423/UG=Hs.296687 Homo sapiens } \\
\text { cDNA FLJ12040 fis, clone HEMBB1001944 }\end{array}$ & 2.87 \\
\hline 204470_at & Chemokine (C-X-C motif) ligand 1 (melanoma growth stimulating activity, $\alpha$ ) & 2.26 \\
\hline
\end{tabular}

B, Genes downregulated by Ro25-7386

\begin{tabular}{|c|c|c|}
\hline Probe set & Gene & Fold change \\
\hline 215655_at & Glutamate receptor, ionotropic, kainate 2 & -3.29 \\
\hline 220327_at & Colon carcinoma-related protein & -2.94 \\
\hline 213910_at & Insulin-like growth factor binding protein 7 & -2.66 \\
\hline 207145_a & Growth differentiation factor 8 & -2.49 \\
\hline 210806_at & KIAA0998 & -2.30 \\
\hline
\end{tabular}

In MDA-MB-231 cells, a total of 335 upregulated genes and 320 downregulated genes modulated by LGD1069 were observed (Table VII); whereas 118 upregulated genes and 432 downregulated genes were modulated by LGD100268 (Table VIII) with alterations in fold induction $>2$-fold. According to the data, several notable genes were identified, including several types of hypothetical protein, zinc finger homeobox $1 \mathrm{~b}$, recombination activating gene 2 and tumor protein D52 (for LGD1069), and zinc finger protein 21, Mdm2, and gonadotropin-releasing hormone 1 (for LG100268).

Confirmation of the alterations of modulation of $R X R \alpha$ target genes of HMECs by RT-qPCR and western blot analysis. The induction of a total of 7 genes by rexinoid (mRNA levels) was confirmed by RT-qPCR assays. These 7 genes are as follows: Integrin $\beta 4$, integrin $\alpha 6, \mathrm{CDH} 1, \mathrm{PAX}, \mathrm{BAX}, \mathrm{FOXO} 3 \mathrm{~A}$ and 
Table VII. Genes up- and downregulated by LGD1069 in MDA-MB-231.

A, Genes upregulated by LGD1069

Probe set

Gene

Fold change

219948_x_at Hypothetical protein FLJ21934

232.43

209672_s_at Hypothetical protein FLJ20323

69.61

207750_at gb:NM_018510.1/DEF=Homo sapiens hypothetical protein PRO1866 (PRO1866), mRNA.

30.50

/FEA=mRNA/GEN=PRO1866/PROD=hypothetical protein PRO1866/DB_XREF=gi:

8924091/UG=Hs.283031 hypothetical protein PRO1866/FL=gb:AF119858.1 gb:NM_018510.1

203603_s_at Zinc finger homeobox 1b

217698_at Consensus includes gb:AV651668/FEA=EST/DB_XREF=gi:9872682/DB_XREF= est:AV651668/CLONE=GLCCSC04/UG=Hs.282480 ESTs

AFFX-r2- E. coli/GEN=bioB/DB_XREF=gb:J04423.1/NOTE=SIF corresponding to nucleotides

10.18

10.11

Ec-bioB2393-2682 of gb:J04423.1/DEF=E.coli 7,8-diamino-pelargonic acid (bioA), biotin synthetase

M_at (bioB), 7-keto-8-amino-pelargonic acid synthetase (bioF), bioC protein, and dethiobiot

205386_s_at Mdm2, transformed 3T3 cell double minute 2, p53 binding protein (mouse)

$$
9.76
$$

216119_s_at Chromosome 20 open reading frame 28

AFFX- E. coli/GEN=bioB/DB_XREF=gb:J04423.1/NOTE=SIF corresponding to nucleotides

BioB-M_at 2482-2739 of gb:J04423.1/DEF=E.coli 7,8-diamino-pelargonic acid (bioA), biotin synthetase (bioB), 7-keto-8-amino-pelargonic acid synthetase (bioF), bioC protein, and dethiobiot

209613_s_at Alcohol dehydrogenase IB (class I), $\beta$ polypeptide

AFFX-r2- E. coli/GEN=bioB/DB_XREF=gb:J04423.1/NOTE=SIF corresponding to nucleotides

Ec-bioB-3_at 2772-3004 of gb:J04423.1/DEF=E.coli 7,8-diamino-pelargonic acid (bioA), biotin synthetase (bioB), 7-keto-8-amino-pelargonic acid synthetase (bioF), bioC protein, and dethiobiot

217194_at Consensus includes gb:AB007970.1/DEF=Homo sapiens mRNA, chromosome 1 specific transcript KIAA0501./FEA=mRNA/DB_XREF=gi:3413945/UG=Hs.223020 Homo sapiens mRNA, chromosome 1 specific transcript KIAA0501

205524_s_at Hyaluronan and proteoglycan link protein 1

215514_at Consensus includes gb:AL080072.1/DEF=Homo sapiens mRNA; cDNA DKFZp564M0616 (from clone DKFZp564M0616)./FEA=mRNA/DB_XREF=gi:5262482/UG=Hs.21195 Homo sapiens mRNA; cDNA DKFZp564M0616 (from clone DKFZp564M0616)

214774_x_at Trinucleotide repeat containing 9

215526_at Consensus includes gb:AL050145.1/DEF=Homo sapiens mRNA; cDNA DKFZp586C2020 (from clone DKFZp586C2020)./FEA=mRNA/DB_XREF=gi:4884356/UG=Hs.225986 Homo sapiens mRNA; cDNA DKFZp586C2020 (from clone DKFZp586C2020)

211091_s_at Neurofibromin 2 (bilateral acoustic neuroma)

221959_at Hypothetical protein MGC39325

206863_x_at gb:U76376.1/DB_XREF=gi:1923234/GEN=HRK/FEA=FLmRNA/CNT=9/TID=Hs.87247.0/ $\mathrm{TIER}=\mathrm{ConsEnd} / \mathrm{STK}=0 / \mathrm{UG}=\mathrm{Hs} .87247 / \mathrm{LL}=8739 / \mathrm{DEF}=$ Homo sapiens activator of apoptosis Hrk (HRK) mRNA, complete cds./PROD=activator of apoptosis Hrk/FL=gb:NM_003806.1 gb:U76376.1

206202_at Mesenchyme homeo box 2 (growth arrest-specific homeo box)

205288_at CDC14 cell division cycle 14 homolog A (S. cerevisiae)

220931_at Hypothetical protein MGC5590

206410_at Nuclear receptor subfamily 0, group B, member 2

207647_at Chromodomain protein, Y-linked, 1///chromodomain protein, Y-linked, 1B

215112_x_at MCF.2 cell line derived transforming sequence-like 2

216775_at Ubiquitin specific protease 53

Ec-bioD-3_at 5312-5559 of gb:J04423.1, not 100\% identical/DEF=E.coli 7,8-diamino-pelargonic acid (bioA), 
Table VII. Continued.

Probe set

Gene

Fold change

biotin synthetase (bioB), 7-keto-8-amino-pelargonic acid synthetase (bioF), bioC pro

220564_at Chromosome 10 open reading frame 59

4.64

211611_s_at Tenascin XB///tenascin XB///cAMP responsive element binding protein-like 1///cAMP

4.61

responsive element binding protein-like 1

AFFX- $\quad$ E. coli/GEN=bioD/DB_XREF=gb:J04423.1/NOTE=SIF corresponding to nucleotides

BioDn-3_at 5286-5570 of gb:J04423.1, not 100\% identical/DEF=E.coli 7,8-diamino-pelargonic acid (bioA), biotin synthetase (bioB), 7-keto-8-amino-pelargonic acid synthetase (bioF), bioC pro

207272_at Zinc finger protein 80 (pT17)

210690_at Killer cell lectin-like receptor subfamily C, member 4

Consensus includes gb:AL050032.1/DEF=Homo sapiens mRNA; cDNA DKFZp566F1224

(from clone DKFZp566F1224)./FEA=mRNA/DB_XREF=gi:4884272/UG=Hs.306307

Homo sapiens mRNA; cDNA DKFZp566F1224 (from clone DKFZp566F1224)

207245_at UDP glycosyltransferase 2 family, polypeptide B17

208014_X_at Neuronal thread protein AD7c-NTP

Heat shock protein, $\alpha$-crystallin-related, B6

Triple functional domain (PTPRF interacting)

206201_s_at Mesenchyme homeo box 2 (growth arrest-specific homeo box)

208019_at Zinc finger protein 157 (HZF22)

204991_s_at Neurofibromin 2 (bilateral acoustic neuroma)

207607_at Achaete-scute complex-like 2 (Drosophila)

AFFX-r2-

E. coli/GEN=bioD/DB_XREF=gb:J04423.1/NOTE=SIF corresponding to nucleotides

Ec-bioD-5_at 5024-5244 of gb:J04423.1/DEF=E.coli 7,8-diamino-pelargonic acid (bioA), biotin synthetase (bioB), 7-keto-8-amino-pelargonic acid synthetase (bioF), bioC protein, and dethiobiot

211315_s_at Calcium channel, voltage-dependent, $\alpha$ 1G subunit

205953_at Leucine-rich repeats and immunoglobulin-like domains 2

207781_s_at Zinc finger protein 6 (CMPX1)

B, Genes downregulated by LGD1069

Probe set

215117_at

217535_at

201691_s_at

207674_at

215172_at

218541_s_at

215350_at

AFFX-

HUMRGE/

M10098_5_at

213652_at

216050_at
Gene

Fold change

$-60.45$

$-16.22$

Consensus includes gb:AV720514/FEA=EST/DB_XREF=gi:10817666/DB_XREF=est: AV720514/CLONE=GLCGSB09/UG=Hs.282721 ESTs, Weakly similar to ALU7_HUMAN ALU SUBFAMILY SQ SEQUENCE CONTAMINATION WARNING ENTRY H.sapiens

Tumor protein D52

Fc fragment of IgA, receptor for

\section{Chromosome 8 open reading frame 4}

Spectrin repeat containing, nuclear envelope 1

H. sapiens/GEN=18S rRNA/DB_XREF=gb:M10098.1/NOTE=SIF corresponding to nucleotides 115-595 of gb:M10098.1/DEF=Human 18S rRNA gene, complete.

Proprotein convertase subtilisin/kexin type 5 
Table VII. Continued.

\begin{tabular}{|c|c|c|}
\hline Probe set & Gene & Fold change \\
\hline & brigham \& women's genetics 1357 expressed [Mus musculus] & \\
\hline 222342_at & $\begin{array}{l}\text { Consensus includes gb:AW979196/FEA=EST/DB_XREF=gi:8170484/DB_XREF=est: } \\
\text { EST391306/UG=Hs.292713 ESTs, Moderately similar to ALU1_HUMAN ALU } \\
\text { SUBFAMILY J SEOUENCE CONTAMINATION WARNING ENTRY H.sapiens }\end{array}$ & -5.41 \\
\hline 205638_at & Brain-specific angiogenesis inhibitor 3 & -5.04 \\
\hline 217464_at & $\begin{array}{l}\text { Consensus includes gb:L48784/DEF=050 Homo sapiens cDNA/FEA=mRNA/DB_ } \\
\text { XREF=gi:1066715/UG=Hs.182426 ribosomal protein S2 }\end{array}$ & -4.97 \\
\hline 205848_at & Growth arrest-specific 2 & -4.86 \\
\hline 206588_at & Deleted in azoospermia-like & -4.75 \\
\hline 213826_s_at & $\begin{array}{l}\text { Consensus includes gb:AA292281/FEA=EST/DB_XREF=gi:1940261/DB_XREF= } \\
\text { est:zt51b03.s1/CLONE=IMAGE:725837/UG=Hs.181307 H3 histone, family 3A }\end{array}$ & -4.74 \\
\hline 220432_s_at & Cytochrome P450, family 39 , subfamily A, polypeptide 1 & -4.48 \\
\hline 209227_at & Tumor suppressor candidate 3 & -4.41 \\
\hline 211712_s_at & Annexin A9///annexin A9 & -4.31 \\
\hline $\begin{array}{l}\text { AFFX- } \\
\text { HUMRGE/ } \\
\text { M10098_M_at }\end{array}$ & $\begin{array}{l}\text { H. sapiens/GEN=18S rRNA/DB_XREF=gb:M10098.1/NOTE=SIF corresponding to } \\
\text { nucleotides 688-1219 of gb:M10098.1/DEF=Human 18S rRNA gene, complete. }\end{array}$ & -4.28 \\
\hline $\begin{array}{l}\text { AFFX- } \\
\text { HUMRGE/ } \\
\text { M10098_3_at }\end{array}$ & Signal recognition particle $68 \mathrm{kDa}$ & -4.20 \\
\hline 202648_at & $\begin{array}{l}\text { gb:BC000023.1/DB_XREF=gi:12652562/FEA=FLmRNA/CNT=966/TID=Hs.298262. } \\
\text { 0/TIER=ConsEnd/STK=0/UG=Hs.298262/LL=6223/UG_GENE=RPS19/DEF= } \\
\text { Homo sapiens, ribosomal protein S19, clone MGC:1630, mRNA, complete cds./PROD= } \\
\text { ribosomal protein S19/FL=gb:M81757.1 g }\end{array}$ & -4.15 \\
\hline 207815_at & Platelet factor 4 variant 1 & -4.15 \\
\hline 205363_at & Butyrobetaine $(\gamma)$, 2-oxoglutarate dioxygenase ( $\gamma$-butyrobetaine hydroxylase) 1 & -4.14 \\
\hline 213856_at & CD47 antigen (Rh-related antigen, integrin-associated signal transducer) & -4.11 \\
\hline 216087_at & MRNA full length insert cDNA clone EUROIMAGE 117929 & -4.11 \\
\hline 211264_at & Glutamate decarboxylase 2 (pancreatic islets and brain, $65 \mathrm{kDa}$ ) & -4.03 \\
\hline 220771_at & Melanoma antigen & -3.83 \\
\hline 220474_at & Solute carrier family 25 (mitochondrial oxodicarboxylate carrier), member 21 & -3.81 \\
\hline 220281_at & Solute carrier family 12 (sodium/potassium/chloride transporters), member 1 & -3.80 \\
\hline 217524_x_at & $\begin{array}{l}\text { Consensus includes gb:AA018923/FEA=EST/DB_XREF=gi:1482314/DB_XREF= } \\
\text { est:ze58d03.s1/CLONE=IMAGE:363173/UG=Hs.261204 ESTs }\end{array}$ & -3.72 \\
\hline 211776_s_at & Erythrocyte membrane protein band 4.1-like 3///erythrocyte membrane protein band 4.1-like 3 & -3.69 \\
\hline 212681_at & Erythrocyte membrane protein band 4.1-like 3 & -3.69 \\
\hline 217333_at & $\begin{array}{l}\text { Consensus includes gb:AL031903/DEF=Human DNA sequence from clone 1032F13 on } \\
\text { chromosome Xq25-26.3. Contains a pseudogene similar to Keratin } 18 \text { (KRT18, } \\
\text { Cytokeratin 18) and ESTs/FEA=CDS/DB_XREF=gi:3766260/UG=Hs.247763 Human DNA } \\
\text { sequence from clone 1032F1 }\end{array}$ & -3.69 \\
\hline 210721_s_at & p21(CDKN1A)-activated kinase 7 & -3.63 \\
\hline 210327_s_at & $\begin{array}{l}\text { Alanine-glyoxylate aminotransferase (oxalosis I; hyperoxaluria I; glycolicaciduria; } \\
\text { serine-pyruvate aminotransferase) }\end{array}$ & -3.57 \\
\hline 206265_s_at & Glycosylphosphatidylinositol specific phospholipase D1 & -3.54 \\
\hline 205847_at & Protease, serine, 22 & -3.52 \\
\hline 202901_x_at & Cathepsin S & -3.42 \\
\hline 204681_s_at & Rap guanine nucleotide exchange factor (GEF) 5 & -3.35 \\
\hline 222227_at & Zinc finger protein 236 & -3.35 \\
\hline 207465_at & PRO0628 protein & -3.34 \\
\hline
\end{tabular}

STAT3; and upregulation of these genes by Ro25-7386 was confirmed as demonstrated in Fig. 6. The alterations in fold induction of protein levels of certain genes were confirmed by western blot analysis; thus upregulation of BAX, CDH1, 
Table VIII. Genes upregulated and downregulated by LG100268 in MDA-MB-231 cells.

A, Genes upregulated by LG100268 in MDA-MB-231

\begin{tabular}{|c|c|c|}
\hline Probe set & Gene & Fold change \\
\hline 219948_x_at & Hypothetical protein FLJ21934 & 88.95 \\
\hline 207750_at & $\begin{array}{l}\text { gb:NM_018510.1/DEF=Homo sapiens hypothetical protein PRO1866 (PRO1866), mRNA./FEA } \\
\text { =mRNA/GEN=PRO1866/PROD=hypothetical protein PRO1866/DB_XREF=gi:8924091/UG } \\
\text { =Hs.283031 hypothetical protein PRO1866/FL=gb:AF119858.1 gb:NM_018510.1 }\end{array}$ & 26.42 \\
\hline 209672_s_at & Hypothetical protein FLJ20323 & 14.63 \\
\hline 215514_at & $\begin{array}{l}\text { Consensus includes gb:AL080072.1/DEF=Homo sapiens mRNA; cDNA DKFZp564M0616 } \\
\text { (from clone DKFZp564M0616)./FEA=mRNA/DB_XREF=gi:5262482/UG=Hs.21195 Homo } \\
\text { sapiens mRNA; cDNA DKFZp564M0616 (from clone DKFZp564M0616) }\end{array}$ & 9.11 \\
\hline 215309_at & $\begin{array}{l}\text { Transcribed locus, weakly similar to XP_092995.4 zinc finger protein } 21 \text { (KOX 14) } \\
\text { [Homo sapiens] }\end{array}$ & 8.12 \\
\hline 214774_x_at & Trinucleotide repeat containing 9 & 7.58 \\
\hline 203603_s_at & Zinc finger homeobox $1 \mathrm{~b}$ & 5.77 \\
\hline 205386_s_at & Mdm2, transformed $3 \mathrm{~T} 3$ cell double minute $2, \mathrm{p} 53$ binding protein (mouse) & 5.20 \\
\hline 205419_at & Epstein-Barr virus induced gene 2 (lymphocyte-specific G protein-coupled receptor) & 4.18 \\
\hline 216978_x_at & $\begin{array}{l}\text { Consensus includes gb:U50277.1/DEF=Human breast cancer suppressor element Ishmael Upper } \\
\text { CP1 mRNA, partial cds./FEA=mRNA/PROD=suppressor element Ishmael Upper CP1/DB_- } \\
\text { XREF=gi:1224126/UG=Hs.121485 Human breast cancer suppressor element Ishmael Upper CP }\end{array}$ & 3.93 \\
\hline 220931_at & Hypothetical protein MGC5590 & 3.81 \\
\hline 219995_s_at & Hypothetical protein FLJ13841 & 3.77 \\
\hline 208076_at & Histone $1, \mathrm{H} 4 \mathrm{~d}$ & 3.6 \\
\hline 214255_at & ATPase, Class V, type 10A & 3.55 \\
\hline 207987_s_at & Gonadotropin-releasing hormone 1 (luteinizing-releasing hormone) & 3.52 \\
\hline 205651_x_at & Rap guanine nucleotide exchange factor (GEF) 4 & 3.46 \\
\hline 220401_at & Hypothetical protein FLJ21369 & 3.39 \\
\hline 207241_at & Chromosome 4 open reading frame 6 & 3.35 \\
\hline 215623_x_at & SMC4 structural maintenance of chromosomes 4-like 1 (yeast) & 3.17 \\
\hline 216119_s_at & Chromosome 20 open reading frame 28 & 3.13 \\
\hline 217194_at & $\begin{array}{l}\text { Consensus includes gb:AB007970.1/DEF=Homo sapiens mRNA, chromosome } 1 \text { specific } \\
\text { transcript KIAA0501./FEA=mRNA/DB_XREF=gi:3413945/UG=Hs.223020 Homo sapiens } \\
\text { mRNA, chromosome } 1 \text { specific transcript KIAA0501 }\end{array}$ & 3.10 \\
\hline 206381_at & Sodium channel, voltage-gated, type II, $\alpha 2$ & 3.09 \\
\hline 212182_at & Nudix (nucleoside diphosphate linked moiety X)-type motif 4 & 2.98 \\
\hline 215112_x_at & MCF. 2 cell line derived transforming sequence-like 2 & 2.94 \\
\hline 213747_at & $\begin{array}{l}\text { Consensus includes gb:AA047234/FEA=EST/DB_XREF=gi:1525134/DB_XREF= } \\
\text { est:zf50b09.s1/CLONE=IMAGE:380345/UG=Hs.223014 antizyme inhibitor }\end{array}$ & 2.84 \\
\hline 221683_s_at & Centrosome protein cep290 & 2.80 \\
\hline 211611_s_at & $\begin{array}{l}\text { Tenascin } \mathrm{XB} / / / \text { tenascin } \mathrm{XB} / / / \mathrm{c} \mathrm{AMP} \text { responsive element binding protein-like } 1 / / / \mathrm{cAMP} \\
\text { responsive element binding protein-like } 1\end{array}$ & 2.74 \\
\hline 205421_at & Solute carrier family 22 (extraneuronal monoamine transporter), member 3 & 2.66 \\
\hline 213764_s_at & Microfibrillar associated protein 5 & 2.62 \\
\hline 217505_at & Hypothetical protein MGC22679 & 2.61 \\
\hline 222320_at & $\begin{array}{l}\text { Consensus includes gb:AW970584/FEA=EST/DB_XREF=gi:8160429/DB_XREF=est: } \\
\text { EST382665/UG=Hs.291033 ESTs }\end{array}$ & 2.61 \\
\hline 216466_at & Neuron navigator 3 & 2.59 \\
\hline AFFX-r2- & E. coli/GEN=bioB/DB_XREF=gb:J04423.1/NOTE=SIF corresponding to nucleotides & 2.55 \\
\hline Ec-bio & 2393-2682 of gb:J04423.1/DEF=E.coli 7,8-diamino-pelargonic acid (bioA), biotin synthetase & \\
\hline B-M_at & (bioB), 7-keto-8-amino-pelargonic acid synthetase (bioF), bioC protein, and dethiobiot & \\
\hline 216775_at & Ubiquitin specific protease 53 & 2.54 \\
\hline 206201_s_at & Mesenchyme homeo box 2 (growth arrest-specific homeo box) & 2.53 \\
\hline AFFX- & E. coli/GEN=bioD/DB_XREF=gb:J04423.1/NOTE=SIF corresponding to nucleotides & 2.48 \\
\hline
\end{tabular}

BioDn-5_at 4980-5256 of gb:J04423.1, not 100\% identical/DEF=E.coli 7,8-diamino-pelargonic acid (bioA), 
Table VIII. Continued.

\begin{tabular}{llr}
\hline Probe set & \multicolumn{1}{c}{ Gene } & Fold change \\
\hline & biotin synthetase (bioB), 7-keto-8-amino-pelargonic acid synthetase (bioF), bioC pro & 2.46 \\
216894_x_at & Cyclin-dependent kinase inhibitor 1C (p57, Kip2) & 2.45 \\
208019_at & Zinc finger protein 157 (HZF22) & 2.44 \\
215803_at & Hypothetical protein FLJ10178 & 2.44 \\
222320_at & CDNA: FLJ23194 fis, clone REC00490 & \\
\hline
\end{tabular}

B, Genes downregulated by LG100268

\begin{tabular}{|c|c|c|}
\hline Probe set & Gene & Fold chan \\
\hline 217237_at & Zinc finger protein 423 & -78.6 \\
\hline 215014_at & $\begin{array}{l}\text { Consensus includes gb:AL512727.1/DEF=Homo sapiens mRNA; cDNA DKFZp547P042 } \\
\text { (from clone DKFZp547P042)./FEA=mRNA/DB_XREF=gi:12224870/UG=Hs.232127 } \\
\text { Homo sapiens mRNA; cDNA DKFZp547P042 (from clone DKFZp547P042) }\end{array}$ & -17.74 \\
\hline 213753_x_at & Eukaryotic translation initiation factor $5 \mathrm{~A}$ & -7.65 \\
\hline 212382_at & Transcription factor 4 & -5.74 \\
\hline $\begin{array}{l}\text { AFFX- } \\
\text { HUMRGE/ } \\
\text { M10098_5_at }\end{array}$ & $\begin{array}{l}\text { H. sapiens/GEN=18S rRNA/DB_XREF=gb:M10098.1/NOTE=SIF corresponding to } \\
\text { nucleotides 115-595 of gb:M10098.1/DEF=Human 18S rRNA gene, complete }\end{array}$ & -5.58 \\
\hline 211712_s_at & Annexin A9///annexin A9 & -5.49 \\
\hline 209227_at & Tumor suppressor candidate 3 & -5.11 \\
\hline 216917_s_at & Synaptonemal complex protein 1 & -4.82 \\
\hline $\begin{array}{l}\text { AFFX- } \\
\text { HUMRGE/ } \\
\text { M10098_M_at }\end{array}$ & $\begin{array}{l}\text { H. sapiens/GEN=18S rRNA/DB_XREF=gb:M10098.1/NOTE=SIF corresponding to } \\
\text { nucleotides 688-1219 of gb:M10098.1/DEF=Human 18S rRNA gene, complete }\end{array}$ & -4.31 \\
\hline 210697_at & Zinc finger protein 257 & -4.11 \\
\hline 215013_s_at & Ubiquitin specific protease 34 & -3.97 \\
\hline 209657_s_at & Heat shock transcription factor 2 & -3.96 \\
\hline 221009_s_at & Angiopoietin-like 4 & -3.90 \\
\hline 205612_at & Multimerin 1 & -3.79 \\
\hline 207613_s_at & Calcium/calmodulin-dependent protein kinase (CaM kinase) II $\alpha$ & -3.55 \\
\hline 37232_at & KIAA0586 & -3.38 \\
\hline AFFX- & Signal recognition particle $68 \mathrm{kDa}$ & -3.37 \\
\hline
\end{tabular}

HUMRGE/

M10098_3_at

204422_s_at

220638_s_at

208098_at

213826_s_at

208453_s_at

207485_x_at

211032_at

220619_at

209318_x_at

201547_at

206996_x_at

220114_s_at

216709_at

203555_at

13267_at
Fibroblast growth factor 2 (basic)

Cas-Br-M (murine) ecotropic retroviral transforming sequence c

Olfactory receptor, family 12 , subfamily D, member $3 / / /$ olfactory receptor, family 12 ,

subfamily $\mathrm{D}$, member $3 / / /$ olfactory receptor, family 5 , subfamily $\mathrm{V}$, member $1 / / /$ olfactory receptor, family 5 , subfamily $\mathrm{V}$, member 1

Consensus includes gb:AA292281/FEA=EST/DB_XREF=gi:1940261/DB_XREF

=est:zt51b03.s1/CLONE=IMAGE:725837/UG=Hs.181307 H3 histone, family 3A

X-prolyl aminopeptidase (aminopeptidase P) 1, soluble

Butyrophilin, subfamily 3, member A1

COBL-like 1///COBL-like 1

Chromodomain helicase DNA binding protein 7

Pleiomorphic adenoma gene-like 1

Jumonji, AT rich interactive domain 1B (RBP2-like)

Calcium channel, voltage-dependent, $\beta 1$ subunit

Stabilin 2

Hypothetical gene supported by BC013370; BC034583 
Table VIII. Continued.

Probe set

Gene

Fold change

201122_x_at Eukaryotic translation initiation factor 5A

213495_s_at gb:AW166067/DB_XREF=gi:6397592/DB_XREF=xf44g10.x1/CLONE=IMAGE: 2620962/FEA=EST/CNT=75/TID=Hs.98614.2/TIER=Stack/STK=51/UG=Hs.98614/

LL=6238/UG_GENE=RRBP1/UG_TITLE=ribosome binding protein 1 (dog 180kD homolog)

220301_at Chromosome 18 open reading frame 14

214837_at

Albumin

209700_x_at Phosphodiesterase 4D interacting protein (myomegalin)

216805_at

Transcribed locus, moderately similar to XP_375099.1 hypothetical protein LOC283585

221671_X_at Immunoglobulin $\kappa$ constant

$\mathrm{FEA}=\mathrm{EST} / \mathrm{CNT}=24 / \mathrm{TID}=\mathrm{Hs} .76230 .2 / \mathrm{TIER}=\mathrm{Stack} / \mathrm{STK}=20 / \mathrm{UG}=\mathrm{Hs} .76230 / \mathrm{LL}=6204 / \mathrm{UG}_{\text {_ }}$

GENE=RPS10/UG_TITLE=ribosomal protein S10

210047_at Solute carrier family 11 (proton-coupled divalent metal ion transporters), member 2

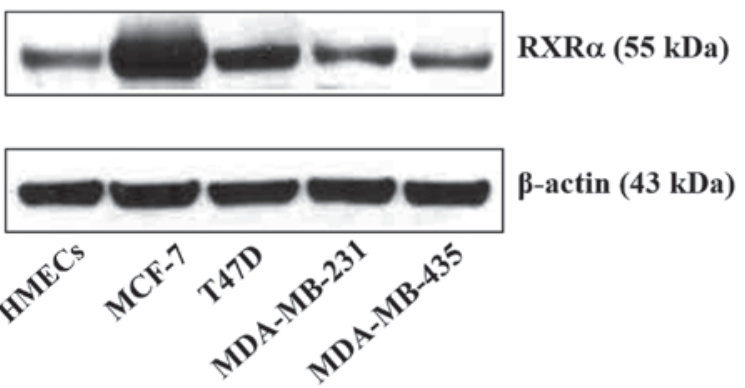

Figure 5. Expression levels of RXR $\alpha$ in normal and malignant breast cells. Whole cell lysates from normal (HMECs) and malignant breast cells (MCF-7, T47D, MDA-MB-231 and MDA-MB-435) were analyzed by western blotting with anti-RXR $\alpha$. The data presented are representative of three independent experiments that gave similar results.



Figure 6. mRNA expression levels of RXR $\alpha$-regulated genes in HMECs (measurement by RT-qPCR). HMECs were treated with Ro25-7386 (1 $\mu \mathrm{M})$ for $12 \mathrm{~h}$. Subsequent to treatment, total RNA samples were extracted and RNA samples were subject to RT-qPCR analysis. Data are presented as the mean of three independent experiments (error bars denote the standard deviation; ${ }^{*} \mathrm{P}<0.05,{ }^{* *} \mathrm{P}<0.01$ and ${ }^{* * * *} \mathrm{P}<0.001$ vs. control). RT-qPCR, reverse transcription-quantitative polymerase chain reaction; DMSO, dimethyl sulfoxide.

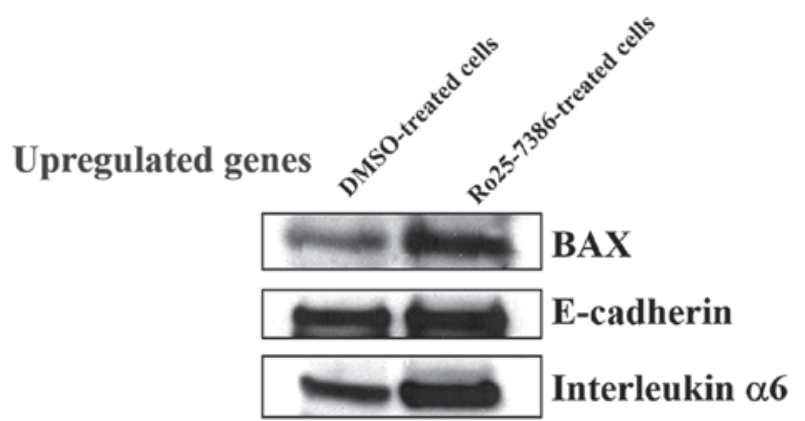

Downregulated genes

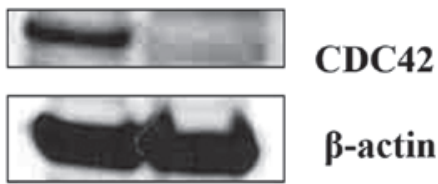

Figure 7. Protein levels of RXR $\alpha$-regulated genes in HMECs measured by western blot analysis. HMECs were treated with Ro25-7386 $(1 \mu \mathrm{M})$ for $24 \mathrm{~h}$. Subsequent to treatment, whole cell lysates were analyzed with anti-BAX, anti-E-cadherin, anti-interleukin $\alpha 6$ and anti-CDC42 antibodies. The data presented are representative of three independent experiments that gave similar results.

interleukin $\alpha 6$ and the downregulation of CDC42 is shown in Fig. 7.

Thorough investigation of the notable genes-CDH1, FOXO3A, BAX (HMEC-Ro25-7386), insulin-like growth factor binding protein 7 and growth differentiation factor 8 (T47D-Ro25-7386) and cathepsin S, TGF 32 , basigin, MCL-1 and BCL2L1 (MCF-7-Ro25-7386), may aid in the clarification of how RXR $\alpha$ agonists function to inhibit breast cell growth. Such notable genes are implicated in breast cancer management and are important for the treatment of breast cancer. 
The current study may aid in the elucidation of novel preventive/therapeutic targets for breast cancer, and may contribute to the development of novel molecules, which may be able to inhibit breast cancer development.

\section{Discussion}

In order to investigate the molecular mechanism by which retinoids suppress breast cancer development, the current study focused upon RXR-specific ligands (rexinoids). These have been reported to suppress breast cancer development with minimal toxicity compared with RAR-specific ligands (21), and it was the RXR $\alpha$ isoform that was specifically focused upon in the present study that serves an important role in tumor suppression.

The human RXR $\alpha$ gene spans over 40 kilobases in size and consists of a minimum of 10 exons separated by introns ranging in size from 700 base pairs (intron 3) to $>7.8 \mathrm{~kb}$ (intron 4) (26). It was observed that all of the cell lines examined expressed RXR $\alpha$. Notably, ER-negative breast cancer cells, which do not respond to retinoid treatment, such as MDA-MB-231 and MDA-MB-435 also expressed RXR $\alpha$. This suggests that $\mathrm{RXR} \alpha$ is non-functional, losing DNA binding activity or failing to recruit essential co-activators required for the activation of the gene in ER-negative cells. Different and inappropriate sub-localization of the receptor may also explain the unresponsiveness of the cells to retinoid treatment.

LGD1069, LG100268 and Ro25-7386 were observed to suppress the growth of breast cells, including the normal HMECs and ER-positive breast cancer cells (MCF-7 and T47D). LGD1069 was observed to induce a mild inhibition of MDA-MB-231 cell growth at a dose of $10 \mu \mathrm{M}$. LG100268 did not affect the cell growth as compared with LGD1069 in all four breast cancer cell lines suggesting its weaker activity. This result indicates that LGD1069 may possess the ability to inhibit the growth of ER-negative breast cancer.

The genes of interest were selected by referring to the PathArt program, which demonstrated the association between genes of several signaling pathways (data not shown). The alterations in gene expression were then analyzed using the Affymetrix microarray (human genome U133A 2.0) to determine which genes are associated with the inhibition of cell growth induced by the rexinoids. Among them, several genes were identified that are involved in cell death, cell growth/maintenance, signal transduction and response to stimulus, including E-cadherin, CtBP1, integrin $\beta 4$, integrin $\alpha 6$, PAX, BAX, FOXO3A, STAT3, collagen type VI $\alpha 3$ and CDC42. It was additionally confirmed that Ro25-7386 upregulates the mRNA expression levels of FOXO3A, E-cadherin, BAX, PAX, STAT3, integrin $\alpha 6$ and integrin $\beta 4$. In addition, Ro25-7386 was observed to increase the levels of BAX, E-cadherin and integrin $\alpha 6$ but reduce the level of CDC42. These results suggest that RXRa may have a role in the prevention and treatment of breast cancer development.

Further investigation regarding the functions of selected genes may aid in the elucidation of novel preventive/therapeutic targets for breast cancer, and may additionally contribute to the development of novel molecules, which may inhibit breast cancer progression.

\section{Acknowledgements}

The current study was supported by the Department of Defense Breast Cancer Research Program Grants (grant no. W81XWH04-1-0505). The present study was also supported in part by the Basic Science Research Program through the National Research Foundation of Korea funded by the Ministry of Education, Science and Technology (grant no. NRF-2012R1A1A3004797) and in part by a grant from the Traditional Korean Medicine Research and Development Project, Ministry of Health \& Welfare, Republic of Korea (grant no. B120014).

\section{References}

1. Siegel R, Ma J, Zou Z and Jemal A: Cancer statistics, 2014. CA Cancer J Clin 64: 9-29, 2014.

2. DeSantis C, Ma J, Bryan L and Jemal A: Breast cancer statistics, 2013. CA Cancer J Clin 64: 52-62, 2014.

3. Abu J, Batuwangala M, Herbert K and Symonds P: Retinoic acid and retinoid receptors: potential chemopreventive and therapeutic role in cervical cancer. Lancet Oncol 6: 712-720, 2005.

4. De Luca LM, Darwiche N, Celli G, Kosa K, Jones C, Ross S and Chen LC: Vitamin A in epithelial differentiation and skin carcinogenesis. Nutr Rev 52: S45-S52, 1994.

5. Gudas LJ, Sporn MB and Roberts AB: Cellular biology and biochemistry of the retinoids. In: The Retinoids: Biology, Chemistry and Medicine. Sporn MB, Roberts AB and Goodman DS (eds), Raven Press, Ltd. New York, pp443-520, 1994.

6. Niles RM: Recent advances in the use of vitamin A (retinoids) in the prevention and treatment of cancer. Nutrition 16: 1084-1089, 2000.

7. Simeone AM and Tari AM: How retinoids regulate breast cancer cell proliferation and apoptosis. Cell Mol Life Sci 61: 1475-1484, 2004.

8. Love JM and Gudas LJ: Vitamin A, differentiation and cancer. Curr Opin Cell Biol 6: 825-831, 1994.

9. Vivat-Hannah V, You D, Rizzo C, Daris JP, Lapointe P, Zusi FC, Marinier A, Lorenzi MV and Gottardis MM: Synergistic cytotoxicity exhibited by combination treatment of selective retinoid ligands with taxol (Paclitaxel). Cancer Res 61: 8703-8711, 2001.

10. Altucci L, Rossin A, Raffelsberger W, Reitmair A, Chomienne C and Gronemeyer H: Retinoic acid-induced apoptosis in leukemia cells is mediated by paracrine action of tumor-selective death ligand TRAIL. Nat Med 7: 680-686, 2001.

11. Chambon P: A decade of molecular biology of retinoic acid receptors. FASEB J 10: 940-954, 1996.

12. Giguère V: Retinoic acid receptors and cellular retinoid binding proteins: Complex interplay in retinoid signaling. Endocr Rev 15: 61-79, 1994.

13. Zusi FC, Lorenzi MV and Vivat-Hannah V: Selective retinoids and rexinoids in cancer therapy and chemoprevention. Drug Discov Today 7: 1165-1174, 2002.

14. Thacher SM, Vasudevan J and Chandraratna RA: Therapeutic applications for ligands of retinoid receptors. Curr Pharm Des 6: 25-58, 2000.

15. Nagpal S and Chandraratna RA: Recent developments in receptor-selective retinoids. Curr Pharm Des 6: 919-931, 2000.

16. Kong G, Kim HT, Wu K, et al: The retinoid X receptor-selective retinoid, LGD1069, down-regulates cyclooxygenase-2 expression in human breast cells through transcription factor crosstalk: implications for molecular-based chemoprevention. Cancer Res 65: 3462-3469, 2005.

17. Nagy L, Thomazy VA, Heyman RA and Davies PJ: Retinoid-induced apoptosis in normal and neoplastic tissues. Cell Death Differ 5: 11-19, 1998.

18. Lippman SM and Lotan R: Advances in the development of retinoids as chemopreventive agents. J Nutr 130 (Suppl 2): 479S-482S, 2000.

19. Gottardis MM, Bischoff ED, Shirley MA, Wagoner MA, Lamph WW and Heyman RA: Chemoprevention of mammary carcinoma by LGD1069 (Targretin): an RXR-selective ligand. Cancer Res 56: 5566-5570, 1996. 
20. Wu K, Zhang Y, Xu XC, et al: The retinoid X receptor-selective retinoid, LGD1069, prevents the development of estrogen receptor-negative mammary tumors in transgenic mice. Cancer Res 62: 6376-6380, 2002.

21. Wu K, Kim HT, Rodriquez JL, et al: Suppression of mammary tumorigenesis in transgenic mice by the RXR-selective retinoid, LGD1069. Cancer Epidemiol Biomarkers Prev 11: 467-474, 2002.

22. Crowe DL and Chandraratna RA: A retinoid $X$ receptor (RXR)-selective retinoid reveals that RXR-alpha is potentially a therapeutic target in breast cancer cell lines and that it potentiates antiproliferative and apoptotic responses to peroxisome proliferator-activated receptor ligands. Breast Cancer Res 6: R546-R555, 2004
23. Farol LT and Hymes KB: Bexarotene: a clinical review. Expert Rev Anticancer Ther 4: 180-188, 2004.

24. Rigas JR and Dragnev KH: Emerging role of rexinoids in non-small cell lung cancer: focus on bexarotene. Oncologist 10: 22-33, 2005.

25. Ma Y, Koza-Taylor PH, DiMattia DA, Hames L, Fu H, Dragnev KH, Turi T, Beebe JS, Freemantle SJ and Dmitrovsky E: Microarray analysis uncovers retinoid targets in human bronchial epithelial cells. Oncogene 22: 4924-4932, 2003.

26. Li G, Walch E, Yang X, Lippman SM and Clifford JL: Cloning and characterization of the human retinoid $X$ receptor alpha gene: conservation of structure with the mouse homolog. Biochem Biophys Res Commun 69: 54-57, 2000. 